\title{
The mini-sigh test: a new haemodynamic test of fluid responsiveness in ICU patients undergoing pressure support ventilation
}

\author{
A Messina ${ }^{*}$, D Colombo ${ }^{1}$, S Romagnoli ${ }^{2}$, E Bonicolini ${ }^{2}, G$ De Mattei ${ }^{1}$, F Longhini ${ }^{3}$, AR De Gaudio ${ }^{2}$, F Della Corte ${ }^{1}$, \\ P Navalesi ${ }^{3,4}$
}

From ESICM LIVES 2015

Berlin, Germany. 3-7 October 2015

\section{Introduction}

Dynamic predictors of fluid responsiveness (FR) perform poorly in ICU patients receiving partial ventilatory assistance. Because these modes of partial support are increasingly used, FR dynamic indexes are applicable only in a few ICU patients [1]. To overcome these limitations, novel approaches for testing FR in ICU have been proposed, such as the passive leg raising and the end-expiratory occlusion. These tests, however, may not always be applicable [2]. During controlled mechanical ventilation, Pulse Pressure (PP) and left ventricle stroke volume are coupled; their variations are due to the reduction of right ventricle stroke volume consequent to ventilator insufflation and are either proportional to the tidal volume and closely related to preload dependence.

\section{Objective}

We hypothesize that during Pressure Support (PS) a brief variation in intrathoracic pressure, such as that produced by a deeper inflation lasting some seconds, would differently affect PP in fluid responder and nonresponders.

\section{Methods}

We investigated 30 ICU hemodynamically unstable patients undergoing PS. The fluid challenge consisted in $500 \mathrm{~mL}$ of Ringer Acetate in 10 minutes. Patients who showed an increase in $\mathrm{CI} \geq 15 \%$ after fluid infusion were considered responders. Hemodynamic measurements were obtained through arterial waveform analysis by PRAM ${ }^{\mathbb{R}}$. The ventilator was set adding to PS a time cycled (4 seconds) pressure-targeted $(15,25$, and 35 $\left.\mathrm{cmH}_{2} \mathrm{O}\right)$ sigh breath. The three preset levels of sigh pressure (SIGH_15; SIGH_25; SIGH_35) were applied in random order according to a pre-generated sequence. The PP variation $(\triangle \mathrm{PP})$ was calculated considering the average PP value in the 20 heartbeats preceding sigh application (baseline), and $10\left(\Delta \mathrm{PP} \_10\right)$ and $\left(\triangle P P \_20\right)$ following the sigh. The lowest PP value obtained during the 20 heartbeats $\left(\Delta \mathrm{PP} \_\right.$Nadir) was compared with the baseline value (example of SIGH_35 in Figure 1).

\section{Results}

There was no significant difference between ROC curves of responders and nonresponders with SIGH_15 and SIGH_25. The AUC of the ROC curve for $\triangle \mathrm{PP} \_$Nadir with SIGH_35 was 0.87 ; a $\triangle \mathrm{PP} \_N a d i r \geq 35 \%$ predicted FR with sensitivity $76 \%$ and specificity $92 \%$; finally, the AUC of $\triangle \mathrm{PP} \_$Nadir was significantly greater than the AUC of $\triangle \mathrm{PP} \_10(0.77 ; \mathrm{p}=0.03)$ and $\Delta \mathrm{PP} \_20(0.75, \mathrm{p}=$ 0.02) (Figure 2).

\section{Conclusions}

In hemodynamically unstable patients undergoing PS, $\triangle P P \_N a d i r$ determined adding SIGH_35, while not SIGH_15 and SIGH_25, allows assessment of FR. 


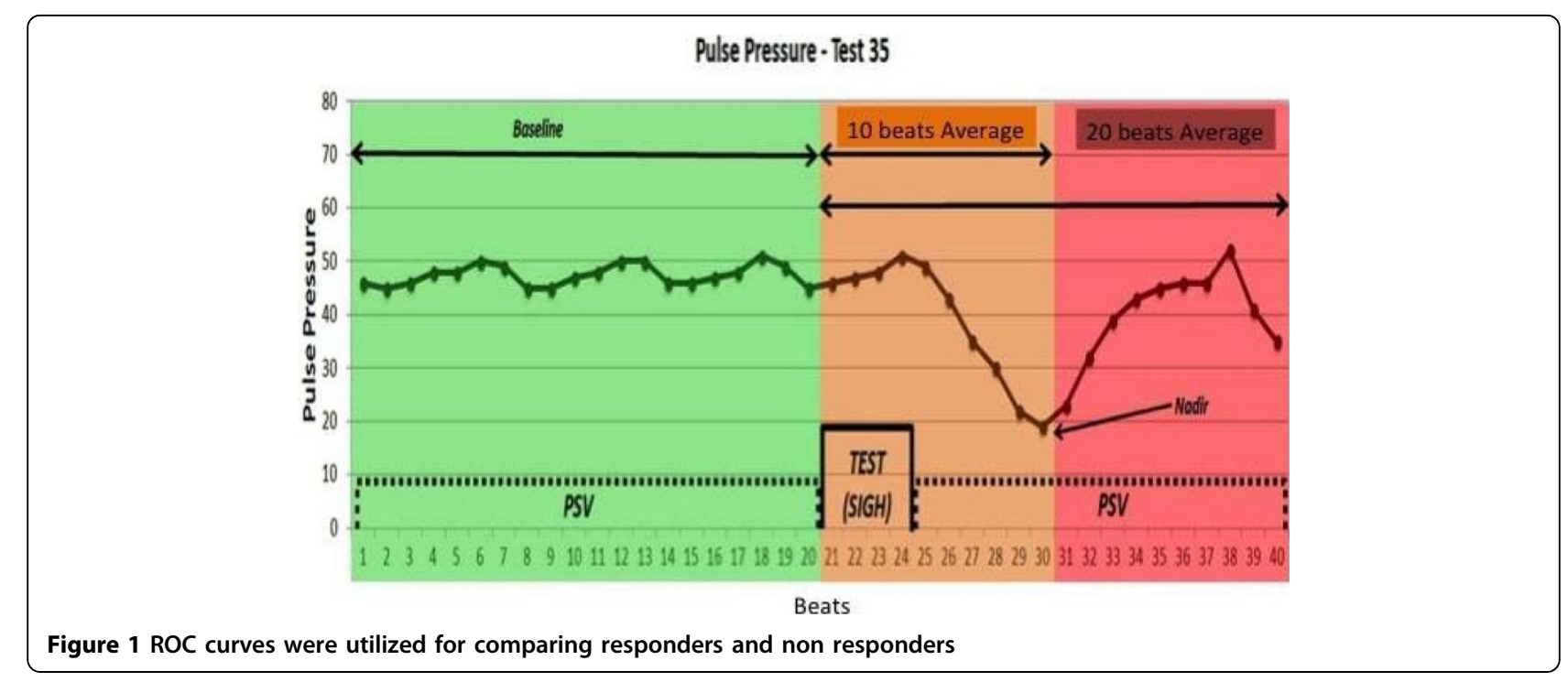

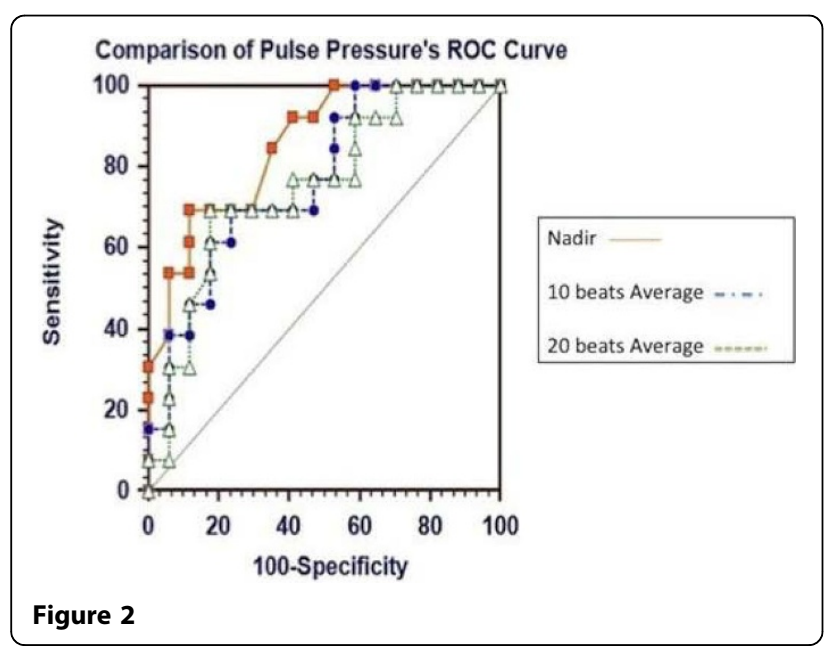

\section{Authors' details}

${ }^{1} \mathrm{AOU}$ Maggiore della Carità, Anesthesiology and Intensive Care, Novara, Italy. ${ }^{2}$ A.O.U Careggi - "Università degli Studi di Firenze", Firenze, Italy. ${ }^{3}$ Ospedale S. Andrea, Vercelli, Italy. ${ }^{4}$ Università del Piemonte Orientale, Medicina

Translazionale, Novara, Italy.

Published: 1 October 2015

\section{References}

1. Mahjoub Y, et al: British Journal of Anaesthesia 2014, 112(4):681-5.

2. Monnet $X$, et al: Critical Care 2013, 17:217.

doi:10.1186/2197-425X-3-S1-A17

Cite this article as: Messina et al.: The mini-sigh test: a new

haemodynamic test of fluid responsiveness in ICU patients undergoing

pressure support ventilation. Intensive Care Medicine Experimental 2015

3(Suppl 1):A17.

\section{Submit your manuscript to a SpringerOpen ${ }^{\circ}$ journal and benefit from:}

- Convenient online submission

- Rigorous peer review

- Immediate publication on acceptance

- Open access: articles freely available online

- High visibility within the field

- Retaining the copyright to your article

Submit your next manuscript at $\boldsymbol{s p r i n g e r o p e n . c o m ~}$ 